Çukurova Üniversitesi Mühendislik Mimarlık Fakültesi Dergisi, 30 (1), $73-78$ ss., Haziran 2015

Çukurova University Journal of the Faculty of Engineering and Architecture, 30(1), pp. 73-78, June 2015

\title{
Balık Kılçı̆̆ı Yöntemi ile Mobil Vinç Kazası Olası Nedenlerinin İncelenmesi
}

\author{
Onur ATALAY ${ }^{1}$, Özen KILIÇ⿻2 \\ ${ }^{1}$ BOTAŞ, Adana \\ ${ }^{2}$ Çukurova Üniversitesi, Mühendislik Mimarlık Fakültesi, Maden Mühendisliği Bölümü, Adana
}

Geliş tarihi: 19.02 .2015

Kabul tarihi: 17.06.2015

\section{Özet}

Yapılan çalışmada BOTAŞ petrol işletmesinde 21.09.2011 tarihinde meydana gelen vinç kazası incelenmiştir. Yapılan çalışma kapsamında mobil vinç kazasının olası nedenleri neden-sonuç analizi olarak da adlandırılan balık kılçığı diyagramı kullanılarak belirlenmeye ve kazanın bir daha tekrarlanmaması için alınması gereken önlemlerin neler olması gerektiği vurgulanmaya çalışılmıştır.

İncelemeler sonunda kazanın çok farklı şekillerde karışık faktörler dizisinden kaynaklandığı görülmüştür

Anahtar Kelimeler: BOTAŞ, Mobil vinç kazası, Balık kılçı̆̆ı diyagramları

\section{Investigation of the Possible Causes of a Mobile Crane Accident via Fishbone Diagrams}

\begin{abstract}
In this study, a mobile crane accident on September 21, 2011 at BOTAŞ petroleum corporation was investigated. Within this study, research has been done to define possible causes of this mobile crane accident using a fish bone diagram otherwise known as a cause-and-effect analysis method. An attempt has been made to emphasize the implementation of corrective actions to prevent reoccurrence.

It has been shown that this incident results from a complicated sequence of factors at the end of this investigation.
\end{abstract}

Keywords: BOTAŞ, Mobile crane accident, Fishbone diagrams

\footnotetext{
* Yazışmaların yapılacağı yazar: Özen KILIÇ, Ç.Ü. Müh.Mim. Fak. Maden Mühendisliği Bölümü, Adana. zenkilic@cu.edu.tr
} 


\section{GíRiş}

İş sağlığı ve güvenliği uygulamalarında amaç, çalışanların bedensel, ruhsal ve sosyal iyilik durumlarını korumak, geliştirmek ve en üst düzeyde sürmesini sağlamaktır. İşyerlerinde sağlık ve güvenlik konularında eğitim çok önemlidir. Giderek hız kazanan teknolojik gelişme ve sanayileşme, iş kazaları ve meslek hastalıklarının da artışı beraberinde getirmiş̧ir. İnsan kaynaklarının önemini anlayan sanayileşmiş ülkeler İş Sağlığı ve Güvenliği'ne büyük yatırımlar yapmış, yeni standartlar üretmiş ve bunları uygulamaya koyarak iş kazalarını en alt düzeylere çekmiştir.

Yapılan çalışma ile BOTAŞ Ceyhan Deniz Terminali’nde 21.09.2011 tarihinde gerçekleşen mobil vinç kazası incelenmiş (Şekil 1); kazanın olası sebepleri belirlenmeye çalıșılmıștır. Kaza, ucuz atlatma şeklinde meydana gelmiştir. Kazanın bir daha olmaması için kaza olduktan sonra mevcut durumun olası sebepleri balık kılçı̆̆ı yöntemi ile belirlenmeye çalışılmıştır. Balık kılç̧ı̆ yöntemi sebep sonuç diyagramı, kazanın belirsizliklerine çözüm getirme, beklenen veya olası risklerin kontrol altına alınmasına ilişkin yöntem ve esasların sistematik bir şekilde tanımlanması ve soruna ilişkin bilinen/bilinmeyen tüm faktörleri ortaya koymak için kullanılmıştır. Yapılan çalışma, bu tip bir kazanın bir daha yaşanmaması, iş güvenliği açısından ortaya çıkabilecek tehlike ve risklerin analiz edilerek kabul edilebilir seviyelerde tutulabilmesi ve alınması gereken önlemlerin olayın olas1 sebeplerini ortaya çıkararak belirlenmesi amacıyla gerçekleştirilmiştir [1].
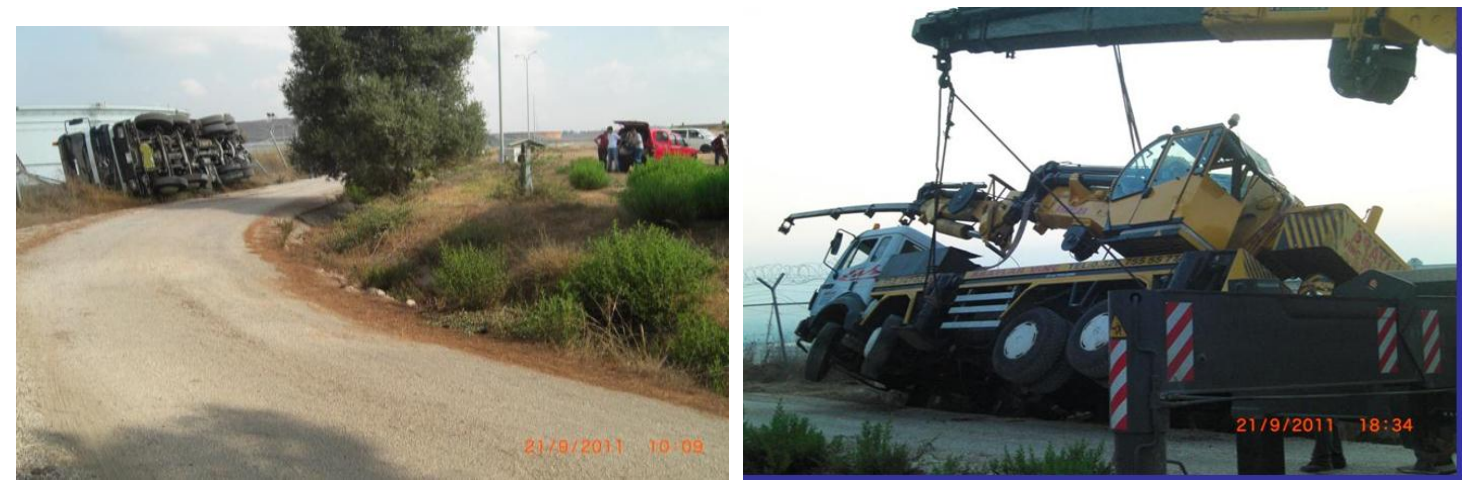

Şekil 1. Mobil vinç kazası

\section{BALIK KILÇIĞI YÖNTEMI (SEBEP SONUÇ DIYYAGRAMI)}

Sebep-sonuç diyagramı, belirli bir problemin veya durumun olası nedenlerini belirlemek için kullanılmaktadır. İstatistiksel yöntemler kullanılarak sonuçlardan hareketle olayın sebeplerine ulaşabilmekte ve çıkan sonuçlarla bunları doğuran sebepler arasındaki çapraz ilişki ortaya çıkarılabilmekte ve görsel olarak sunulabilmektedir. Bu işlem en kolay sebep-sonuç diyagramları ile yapabilmektedir [2]. Çizilen grafiğin görüntüsü balık kılçığını andırdığından, bu grafik balık kılçı̆̆ı grafiği olarak da adlandırılmaktadır. Ishikawa diyagramı, belirli bir soruna neden olan tüm faktörleri ortaya çıkarmaya ve sonuca en fazla etki eden faktörü bulup iyileştirmeye yön veren bir tekniktir. Teknik, Japon toplam kalite uzmanı Kaoru Ishikawa tarafindan geliştirilmiş ve karar verme bilimine sunulmuştur [3]. Ishikawa diyagramı bireysel sorunlardan kurumsal boyutlara kadar herhangi bir konuda uygulanabilen, uygulaması basit, oldukça yararlı ve kapsamlı bir sorun çözme tekniğidir. Beyin fırtınası tekniği ile birleştirildiğinde daha etkin sonuçlar vermektedir.

Bu grafik çeşidi sayesinde [4]; 
- Problem çözme sürecinin daha düzenli hale getirilmesi,

- Problem hakkında bütün bilinenlerin ortaya konması, bilinenlerden bilinmeyene doğru sistematik bir yaklaşım olması,

- Problemle doğrudan deneyimi olan kişilerin uzmanlığından yararlanılması, mümkün olabilmektedir.

Özden [5]'in tanımlamış olduğu ve sebep-sonuç diyagramlarını oluştururken izlenilecek olan aşamalar aşağıda yer almaktadır;

Dağılım analizinde, önce geliştirilmesi amaçlanan problem belirlenmelidir. Problem belirlendikten sonra Şekil 2'de verildiği üzere sebep-sonuç diyagramının ana çizgisi oluşturulur ve çözümü bulunması istenen ana problem yazılır.

\section{PROBLEM}

Şekil 2. Sebep sonuç diyagramı-aşama 1

Diyagram oluşturulurken, çevresel ve işletme içi faktörler ayrıntılı olarak incelenmelidir. Problemin kaynaklandığı muhtemel sebepler belirlenerek ana başlıklar altında toplanmalıdır. Tüm sebeplerin aktarılabilmesi için problemle ilgili olan herkesin görüşü alınmalıdır. Üretim sektöründe genellikle belirlenen bu ana sebepler metot, makine, insan gücü ve malzeme olarak gruplandırılmaktadır. Fakat yapılan analizlere göre bu sebepler farklılaşabilmektedir. Belirlenen ana sebepler Şekil 3'de gösterildiği gibi grafiğe eklenir [2].

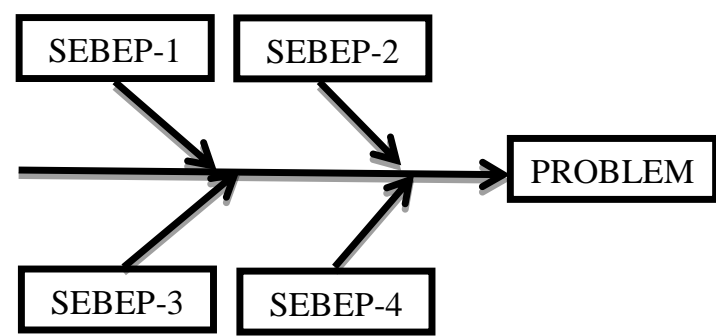

Şekil 3. Sebep sonuç diyagramı-aşama 2

Proje kapsamında olan tüm üyeler beyin firtınası yöntemiyle bulunan bu ana sebeplerin alt sebeplerini belirler. $\mathrm{Bu}$ aşamada önemli olan nokta, beyin firtınasına katılan kişilerin proje ve problem hakkında bilgi sahibi olmalarıdır. $\mathrm{Bu}$ sayede gerçek sebeplere ulaşllabilmektedir. Şekil 4'de grafiğin bu evreden sonraki durumu verilmektedir [2].

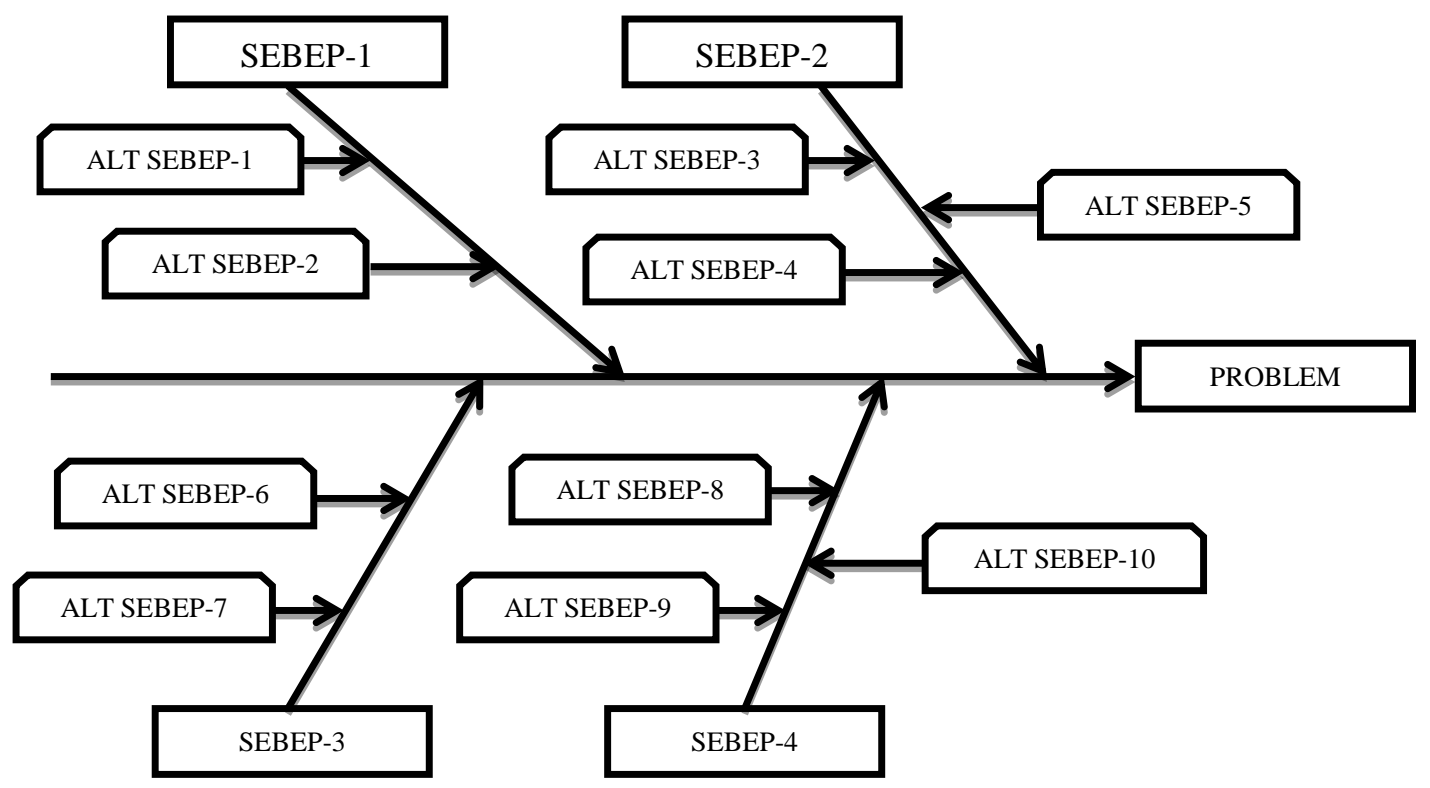

Şekil 4. Sebep sonuç diyagramı-aşama 3 
Sebep-sonuç diyagramlarının çizilmesinde yapılan son aşamada; belirlenen ana sebeplere uygun olarak yazılmış olan alt sebepler beyin firtınasına katılan kişiler tarafindan değerlendirilir. Kişiler teker teker, kendi önem siralarına uygun puan verirler. Puanlama sonucunda, her alt sebebe kişilerin belirledikleri toplam not verilir. En çok oyu alan alt sebep belirlenir, kök neden analizine göre problemin kaynak noktası en çok oyu alan alt sebeptir. En çok oyu alan bu alt sebepten sonra iyileştirme ve sebebi ortadan kaldırmaya yönelik çalışmalar yapılmalıdır. Zaman içinde, elde edilen diyagramın güncelleştirilmesi gerekmektedir.

\section{BULGULAR}

Mobil vinç kazası, 21.09.2011 tarihinde, BOTAŞ Ceyhan Adana tank sahasında meydana gelmiş olup, ucuz atlatma şeklinde sonuçlanmıştır. Buna istinaden mobil vinç kazasının olası nedenleri, neden-sonuç analizi olarak da adlandırılan, balık kılçığı diyagramı kullanılarak belirlenmeye çalıșılmıştır. Bu yapılan risk değerlendirmesi ile riskin derecesi kabul edilebilir seviyeye düşürülmüştür. Böylelikle bir daha kaza olmaması için gerekli tedbirler sağlanmıştır.

Kaza, mobil vincin 1. çalışma bölgesindeki işini bitirip, saç stok sahasından taşıyıcı kamyona saç yüklemek için, açıp kapatmak zahmetli olduğu için kaldırma bomunu (kaldırma kolunu) tam kapatmadan yola çıkmış, kestirme yol diye keskin virajlı yol güzergahını kullanmış ve viraja gelince açık durumundaki kolu yol kenarındaki çam ağacına takılmasın diye, aceleyle ve yardımcı kullanmadan geri geri giderken, yol kenarındaki çukura arka tekerlerin kayması sonrası, vincin komple sağ tarafa devrilmesi ile meydana gelmiştir.

Vincin açık bomu sağ tarafta daha aşağıya kaymıştır. Kazada herhangi bir yaralanma olmamıştır. Ancak Vincin devrildiği sağ tarafta yaklaşık $50 \mathrm{~m}$ yükseklikte kod farkı vardır. Aşağıdaki bölge ise, ekipmanların bulunduğu başka bir tehlikeli çalışma alanıdır. Şans eseri aşağıya yuvarlanmadan kenarda takılıp kalmıştır. Vincin aşağıya yuvarlanmasının sonuçları çok kötü olabilirdi. Kaza ucuz atlatılmıştır.
Mobil vinç kazasının balık kılçığı risk değerlendirme yöntemiyle değerlendirilmesi ile;

- Kazanın belirsizliklerine çözüm getirilmesi,

- Soruna ilişkin bilinen ve ya bilinmeyene tüm faktörlerin ortaya konulması,

- İleride oluşabilecek potansiyel tehlikelerin ve bunlara ilişkin risklerin belirlenmesi,

- Beklenen veya olası risklerin kontrol altına alınmasına ilişkin yöntem ve esasların sistematik bir şekilde tanımlanması,

- İş kazaları ve meslek hastalıkların asgari seviyelere indirilmesi hedeflenmiştir.

Vinç kazasında, balık kılçı̆̆ı yöntemi ile tehlike ve risklerin değerlendirilmesi Şekil 5'te belirtilen şemaya göre gerçekleştirilmiştir.

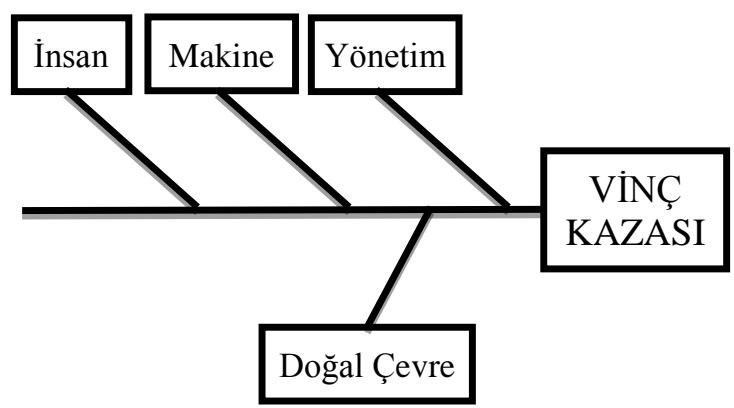

Şekil 5. Tehlike tanımlama ve risk değerlendirme programı akış şeması

Problemin Belirlenmesi:

Mobil vinç, 1. sac stok sahasına doğru giderken sağ tarafa doğru devrilerek kaza meydana gelmiştir.

- Ana problem, vincin sağ tarafa doğru devrilerek iş kazasının meydana gelmiş olmasıdır.

- Kaza meydana geldiği sirada mobil vincin kaldırma bomu yarı açık durumdadır.

- Vincin kaza yaptığı yolun keskin virajlı bir yol olduğu gözlemlenmiştir.

- Yüklenici firma, dişarıdan harici vinç kiralamıştır. Yüklenici firma, kendi vinç operatörü ile çalışma yapmaktadır. Operatör araca yabancılık çekmiş olabilir.

- Vinç operatörünün operatörlük belgesi aynı yıl içerisinde alınmıştır. Operatörün yaptığ 1 iş kolundaki deneyimi azdir.

- Güvenli yol güzergâhı net olarak belirlenmemiştir. 
- Operatör yardım almadan geri manevra yapmiştır.

- Kontrol elemanı vinci etkin olarak takip etmemiştir.

Kaza sebepleri belirlendikten sonra yapılacak çalışmalarla kaza olduktan sonraki mevcut durum ile ilgili risk değerlendirmesi, yasal yükümlülüklere ve işyerinin politikasına uygun, kayıp veya yaralanma oluşturmayacak şekilde kontrol önlemleri ile kabul edilebilir risk seviyesine düşürülür. Mobil vinç kazasının sebep sonuç diyagramı Şekil 6'da verilmiştir. Balık kılçı̆̆ı yöntemi uygulanarak kazaya sebep olabilecek ana nedenler ve hataya sebep olabilecek alt nedenler önem sırasına göre ayrılmıştır. Buna göre; operatörün bomu açık halde iken vincin kontrol edilmeden yola çıkması, operatörün umursamazlığı, manevracının araçta kalması, operatörün güvenli şekilde araç kullanmaması, acelecilik, operatörün deneyimsiz olması, önceden güzergah belirlenmeyip güzergahın virajlı olması, yönetim tarafindan yasal muayeneler dışında araç kontrolü yapılmaması, yönetim tarafindan güvenli yol güzergahının belirlenmemesi, yönetim tarafından iki ayrı işte tek araç, tek personel olarak planlama yapılması, yönetim tarafindan işlerin daha hızlı yapılma politikası, yönetim tarafından tehlikeli sınıfta çalışılan işyerinde deneyimsiz operatör çalıştırıldığı, yönetim tarafindan uzmanlaşmamış kontrol elemanının çalıştırılması doğal çevre koşullarında ise, mobil vincin güzergahında yolda manevrasını engelleyen çam ağacinın olması ve bu yolun kaygan olması kazanın sebepleri olarak sayllabilmektedir.

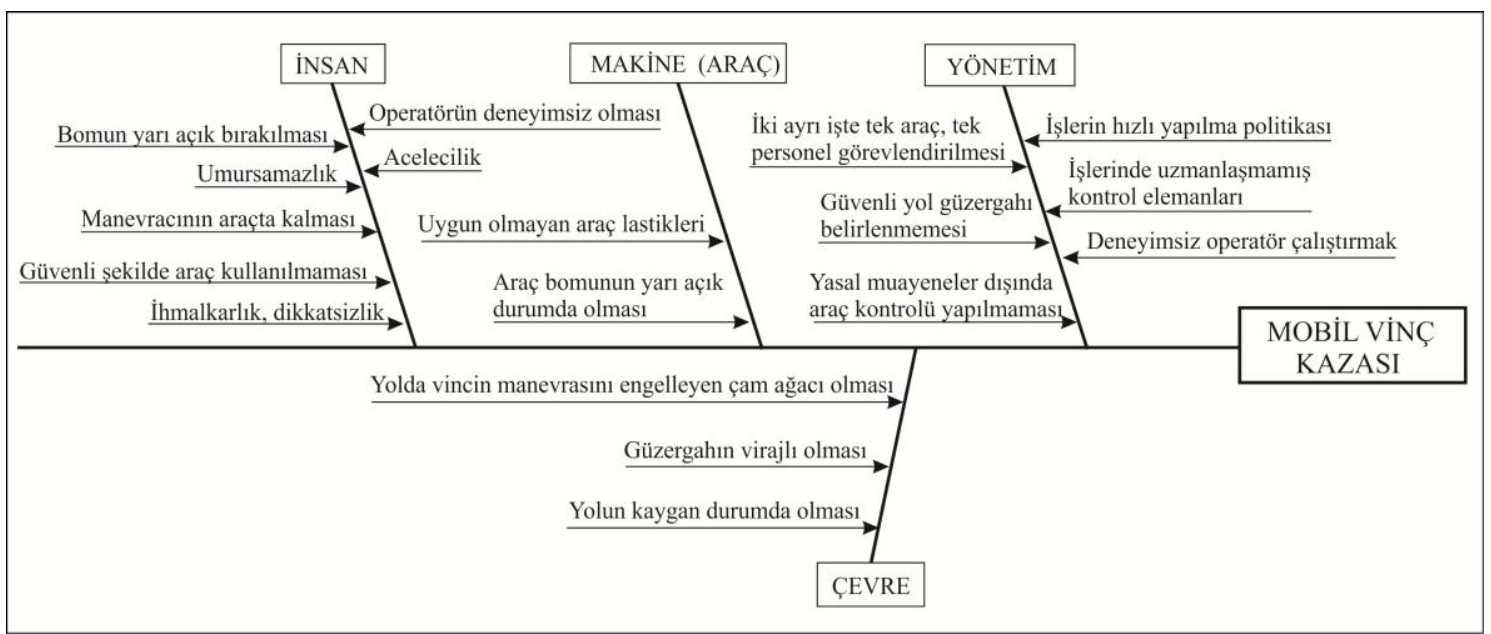

Şekil 6. Mobil vinç kazasının sebep-sonuç diyagramı

\section{SONUÇLAR VE ÖNERILLER}

İş kazalarının \%88'i tehlikeli hareketlerden, \%10'u tehlikeli durumlardan, \%2'si kaçınılmaz ve sebebi bilinmeyen hareketlerden oluşmaktadır. Bu prensip iş güvenliği sorumlularına özellikle tehlikeli hareketler üzerinde yoğunlaşmalarının gerektiğini açıkça gösterebilir.

Balık kılçığı yöntemi mobil vinç kazasının sebepsonuç ilişkilerini daha net bir şekilde görülmesi ve kazaya neden olan tehlikelerin belirlenmesi amacıyla kullanılmıştır. Mobil vinç kazası ucuz atlatma şeklinde gerçekleşmiş ve bu kazaya sebep olan tüm faaliyetleri bir arada görme ve aralarındaki ilişkileri inceleme firsatı sunmuştur.

Kazanın ana sebeplerinin başında yönetsel yetmezliğin göstergelerinin olduğu görülmektedir. Çok tehlikeli sınıfta deneyimsiz operatör çalıştırılmıştır. Tehlikelerin gerektirdiği önlemlerin alınmadığı belirlenmiştir.

Yapılan incelemeler sonucunda, çalışanların eğitimi, denetimi ve talimatların artırılması, önce iş 
güvenliği bilinci ile yetkin ve deneyimli uzman personel çalıştırılması ile bu tür kazaların önüne geçilebilmesinin mümkün olabileceği kanısına varılmıştır.

İşyerlerinde kaza önleme politikası uygulanması gerekmektedir. Her kademede çalışan yönetim elemanları İSG'yi üretimin bir parçası olarak kabul etmeli ve bunu kararları, davranışları ile OHSAS 18001'deki uygulamalar ile desteklemelidir. Mevzuat yükümlülüklerinin karşılanmasına paralellik göstererek OHSAS 18001 standartları uygulanarak prosedür uygulamayı benimsemelidir. İşyerlerinde güvenlik politikası veya kurallarının uygulanmasında çaba gösterilmelidir. Kontrol ve denetlemenin etkili ve yeterli bir şekilde yapılması gerekmektedir. Eğitimler gerektiği gibi verilmeli ve bunların uygulanması sağlanmalıdır. Her kazadan sonra inceleme yapılmalı ve-olaylarla raporlar arasında neden açısından ilinti olması gerekmektedir. Yönetimsel olarak bütün risklerin ortadan kaldırılması için gerekli risk değerlendirme çalışmaları yapılması gerekmektedir. Geçmiş kayıtların incelenmesi, talimat yazılması, İş kazalarına ait İş güvenliği kurul toplantılarının yapılmasının sağlanmalıdır. Kaza olmadan önce önleyici (proaktif) yaklaşımlarda bulunulmalı ve acil durum planı hazırlanarak gerekli çalışmalar yapılmalıdır.

\section{KAYNAKLAR}

1. Atalay, O., 2014. Mobil Vinç Kazası Sebeplerinin Risk Analizi Yöntemleri ile İncelenmesi, Çukurova Üniversitesi, Fen Bilimleri Enstitüsü, Yüksek Lisans Tezi, s 159, Adana.

2. Çelikçapa, F., 1993. Toplam Kalite Kontrolü ve Bursa Bölgesindeki Kalite Kontrol Uygulamalarına İlişkin Bir Araştırma, Busiad Yayınları, s. 48-49.

3. Ishikawa, K., 1991. Guide to Quality Control, Asian Productivity Organisation.

4. Akşit, C., 1999. Türk silahlı Kuvvetlerinde Toplam Kalite Uygulamalar1-2, Ankara: Genel Kurmay Basımevi.

5. Özden, Y., 2005. Eğitimde Yeni Değerler, Pegema Yayınc1lık, Ankara. 